\title{
Visible light activated Photocatalytic TaON coatings deposited via Pulsed- DC Magnetron Sputtering
} M Ratova $a^{\mathrm{a}, \mathrm{b}}$, GT West ${ }^{\mathrm{b}}$, PJ Kelly ${ }^{\mathrm{b}}$

\author{
a School of Chemistry and Chemical Engineering, David Keir Building, Stranmillis Road, \\ Belfast, BT9 5AG, UK \\ b Surface Engineering Group, Manchester Metropolitan University, John Dalton Building, \\ Chester Street, Manchester M1 5GD, UK
}

Corresponding author: M Ratova, School of Chemistry and Chemical Engineering, David Keir Building, Stranmillis Road, Belfast, BT9 5AG, UK, tel. +44 289097 4453, e-mail address marina_ratova@hotmail.com

\begin{abstract}
Tantalum oxynitride coatings were deposited via reactive pulsed-DC magnetron sputtering. The nitrogen content in the coatings, governed by the flow rate of nitrogen gas, affected the resulting crystallinity of the annealed films and their optical band gap. The photocatalytic activity, as measured via organic dye degradation, was strongly linked to these properties, with those coatings containing the highest nitrogen levels exhibiting visible light activity. Upon comparison, this activity was found to be significantly higher than commercial titanium dioxide photocatalysts.
\end{abstract}

\section{Keywords}

Tantalum oxynitride; magnetron sputtering; photocatalytic coatings; visible light activity; methylene blue. 


\section{Main text}

Tantalum-based materials have attracted increasing interest amongst researchers as alternative photocatalytic materials. Several works have been published on tantalum oxide $\mathrm{Ta}_{2} \mathrm{O}_{5}$ as a photocatalytic material [1-3], however its high band gap (4 eV and higher - [1]) significantly limits its application. Tantalum oxynitride films have recently drawn some attention as they are expected to combine properties of tantalum oxide and tantalum nitride, and therefore may exhibit potentially interesting electrical, optical and mechanical properties $[4,5]$. It has been reported that tantalum oxynitride may find application as a novel visible light photocatalyst [611]. The photocatalytic properties of the most popular photocatalytic materials, titanium dioxide and zinc oxide, are limited in the sense that a UV light source must be used to activate the catalytic behaviour due to relatively high band gap values of these compounds ( 3.2 and $3.0 \mathrm{eV}$, respectively). Several methods, can be used for shifting the photocatalytic activity of $\mathrm{TiO}_{2}$ and $\mathrm{ZnO}$ towards the visible range, such as doping $[12,13]$ or photosensitization [14]. However, the majority of modified photocatalysts are still able to use only a small fraction of the visible light spectrum (typically 400-420 nm). Therefore tantalum oxynitride with its low band gap (reportedly in the range of $1.5-2.4 \mathrm{eV}[4,9]$ ) may be a suitable alternative to other, more popular photocatalysts where visible light activity is required.

Reactive magnetron sputtering is one of the most widely used techniques for the production of oxide and nitride coatings due to its relatively low cost, process stability and versatility. Magnetron sputtering is often reported to be used for the production of tantalum oxide [1] and oxynitride coatings $[15,16]$ although the photocatalytic application of reactively sputtered TaON coatings is not widely reported [4]. Therefore, the aims of this study were to find experimental conditions that allow the deposition of stoichiometric tantalum oxynitride coatings using reactive magnetron sputtering, to test their photocatalytic activity under visible light irradiation and compare their photocatalytic efficacy against a commercially available photocatalytic glazing product. 
All coatings were deposited in a Teer Coatings Ltd. UDP450 sputtering rig using a vertically mounted rectangular planar magnetron with a $300 \mathrm{~mm} \times 100 \mathrm{~mm}$ tantalum target $(99.5 \%$ purity $)$ bonded to a copper backing plate. The magnetron was driven in mid-frequency pulsed DC sputtering mode using an Advanced Energy Pinnacle Plus power supply at a constant timeaveraged power of $1 \mathrm{~kW}$, pulse frequency of $100 \mathrm{kHz}$ and a duty of $50 \%$. The reactive sputtering process was carried out in an argon / oxygen / nitrogen atmosphere at a pressure of $0.3 \mathrm{~Pa}$. The oxygen flow rate was controlled using a Megatech Reactaflo ${ }^{\mathrm{TM}}$ optical emission monitoring system set for $30 \%$ and $35 \%$ of the full metal signal; the flow of the other two gases was set using mass-flow controllers ( $\mathrm{Ar} 40 \mathrm{sccm}, \mathrm{N}_{2}$ at $10 \mathrm{sccm}$ and $20 \mathrm{sccm}$ ). Soda-lime glass slides, used as substrates, were ultrasonically pre-cleaned in propan-2-ol and mounted on a rotatable substrate holder at $100 \mathrm{~mm}$ distance from the target. The rotation speed of the substrate holder was fixed at $5 \mathrm{rpm}$ for all runs.

The coatings were annealed in air at a temperature of $873 \mathrm{~K}$ for $30 \mathrm{~min}$, followed by gradual cooling for 8-9 hours to avoid thermal stresses in the coatings.

The coatings were analysed with scanning electron microscopy (SEM) (FEI Quanta FEG). The composition of the coatings was estimated with EDX (Aztec-based XACT system, Oxford instruments that enables standardless quantification). The crystallinity of the coatings was determined with X-ray diffraction (Panalytical Xpert powder in grazing incidence mode at $3^{\circ}$ ). The band gap values of the coatings were calculated using Tauc plot method using transmittance of the coatings (determined with an Ocean Optics 2000+ spectrophotometer). Surface roughness of the coatings was measured using MicroXAM white light surface profilometry.

The photocatalytic properties of the coatings were assessed using the methylene blue (MB) photo-degradation test. An aqueous solution of methylene blue has strong absorption peak at $665 \mathrm{~nm}$; monitoring of the peak height can be used for quantitative assessment of a sample's photocatalytic properties. The absorption peak height was continuously monitored for 1 hour 
using a spectrophotometer. According to the Lambert-Beer law, the concentration decay of the dye is proportional to the absorbance decay. Photocatalytic decomposition of methylene blue was approximated to first order kinetics:

$$
\ln \left[\frac{C_{0}}{C}\right]=k_{a} t
$$

Where $\mathrm{C}_{0}$ and $\mathrm{C}$ are concentrations of methylene blue solutions prior to the experiment (time $=$ 0 ) and at the time of experiment, respectively; $k_{a}$ is first order reaction constant; $t$ is a time of experiment. Therefore the reaction constant can be determined from the gradient of the $\ln \left(\mathrm{A}_{0} / \mathrm{A}\right)$ versus time curves.

Prior to photocatalytic activity measurement, samples of the same geometrical size $(2.5 \times 1.5$ $\left.\mathrm{cm}^{2}\right)$ were immersed in a conditioning solution of MB $(1.5 \mu \mathrm{mol} / 1)$ for $30 \mathrm{~min}$ in the dark to establish equilibrium adsorption/desorption conditions at the sample surface during the test. The same concentration of MB solution - $1.5 \mu \mathrm{mol} / 1$ - was used for the photocatalytic test; the concentration was determined experimentally to reflect the photocatalytic response of these coatings during a 1 hour experiment. The visible light was produced using a fluorescent light source $(2 \times 15 \mathrm{~W}$ Ushio fluorescent lamps (USHIO, Japan) combined with $395 \mathrm{~nm}$ long pass filter (Knight Optical, UK) to block the UV component. The emission spectrum of the light source used for photocatalytic testing is shown in Figure 1. To prove that MB discoloration is caused by photocatalytic decomposition of the dye, rather than any side reactions, a series of reference tests was carried out, including testing under visible light with a blank sample and testing each sample in dark conditions. The results showed that in either case, during a 1 hour experiment the absorption value of $\mathrm{MB}$ did not change by more than $1 \%$, therefore these values could be neglected in further calculations of photocatalytic activity. The sample of commercial photocatalytic coating was tested under identical conditions for comparison. 


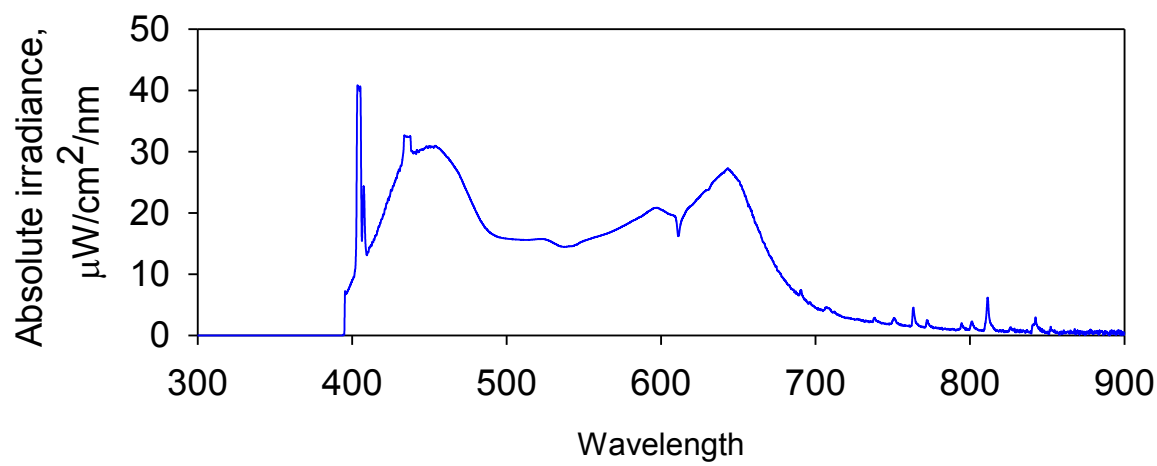

Figure 1. Spectrum of the fluorescent light source with UV filter used for photocatalytic experiments

Varying the oxygen and nitrogen content allowed significant variations in colour and composition of the coatings. Table 1 summarises the deposition conditions, appearance, elemental composition and thickness. According to the EDX results and coating appearance, it may be concluded that coatings $\mathrm{C}$ and $\mathrm{D}$ were predominantly tantalum oxide coatings with a much lower content of nitrogen, compared to samples A and B, due to their high transparency and lack of colouration. SEM images of the coatings are shown in Figure 2. It can be seen that coatings $\mathrm{A}$ and $\mathrm{B}$, produced with a higher nitrogen flow rate, have a visibly rougher and more porous surface with multiple cracks evident. The surface of the samples $\mathrm{C}$ and $\mathrm{D}$ produced with a lower $\mathrm{N}_{2}$ flow rate were relatively smooth, uniform and defect-free, as expected for tantalum oxide coatings [1]. Multiple cracks on the coating surfaces formed as a result of the hightemperature annealing process can be seen on either pair of samples.

\begin{tabular}{|l|l|l|l|l|}
\hline Sample ID & Sample A & Sample B & Sample C & Sample D \\
\hline OEM, \% of & & & & \\
full metal & $30 \%$ & $35 \%$ & $30 \%$ & $35 \%$ \\
signal & & & & \\
\hline N flow, sccm & $20 \mathrm{sccm}$ & $20 \mathrm{sccm}$ & $10 \mathrm{sccm}$ & $10 \mathrm{sccm}$ \\
\hline
\end{tabular}




\begin{tabular}{|c|c|c|c|c|}
\hline $\begin{array}{l}\text { Thickness, } \\
\mathrm{nm}\end{array}$ & 482 & 455 & 586 & 540 \\
\hline $\begin{array}{l}\text { Ta content, } \\
\text { at. } \%\end{array}$ & $29.72 \%$ & $31.26 \%$ & $22.88 \%$ & $30.02 \%$ \\
\hline $\begin{array}{l}\text { O content, at. } \\
\%\end{array}$ & $62.44 \%$ & $59.56 \%$ & $76.18 \%$ & $65.06 \%$ \\
\hline $\begin{array}{l}\mathrm{N} \text { content, at. } \\
\%\end{array}$ & $7.84 \%$ & $9.18 \%$ & $0.94 \%$ & $4.92 \%$ \\
\hline $\begin{array}{l}\text { Visual } \\
\text { appearance }\end{array}$ & $\begin{array}{l}\text { Dark- } \\
\text { brown, } \\
\text { transparent }\end{array}$ & $\begin{array}{l}\text { Dark-brown, } \\
\text { low } \\
\text { transparency }\end{array}$ & $\begin{array}{l}\text { Light- } \\
\text { yellow, } \\
\text { transparent }\end{array}$ & $\begin{array}{l}\text { Light- } \\
\text { brown, } \\
\text { transparent }\end{array}$ \\
\hline $\begin{array}{l}\text { Predominant } \\
\text { crystal phase } \\
\text { and } \\
\text { orientation }\end{array}$ & $\begin{array}{l}\text { Tantalum } \\
\text { oxide (001) } \\
\text { / Tantalum } \\
\text { oxynitride } \\
(111)\end{array}$ & $\begin{array}{l}\text { Tantalum } \\
\text { oxynitride } \\
(110) /(002)\end{array}$ & Amorphous & Amorphous \\
\hline Band gap, eV & 1.87 & 1.67 & 3 & 2.63 \\
\hline $\begin{array}{l}\text { Surface } \\
\text { roughness, } \\
\mu \mathrm{m}\end{array}$ & 0.06169 & 0.06578 & 0.01256 & 0.01960 \\
\hline $\mathrm{k}_{\mathrm{a}} \times 10^{5}, \mathrm{~s}^{-1}$ & 3.5 & 2 & 0 & 0.6 \\
\hline
\end{tabular}

Table 1. Overview of deposition conditions and properties of the coatings 

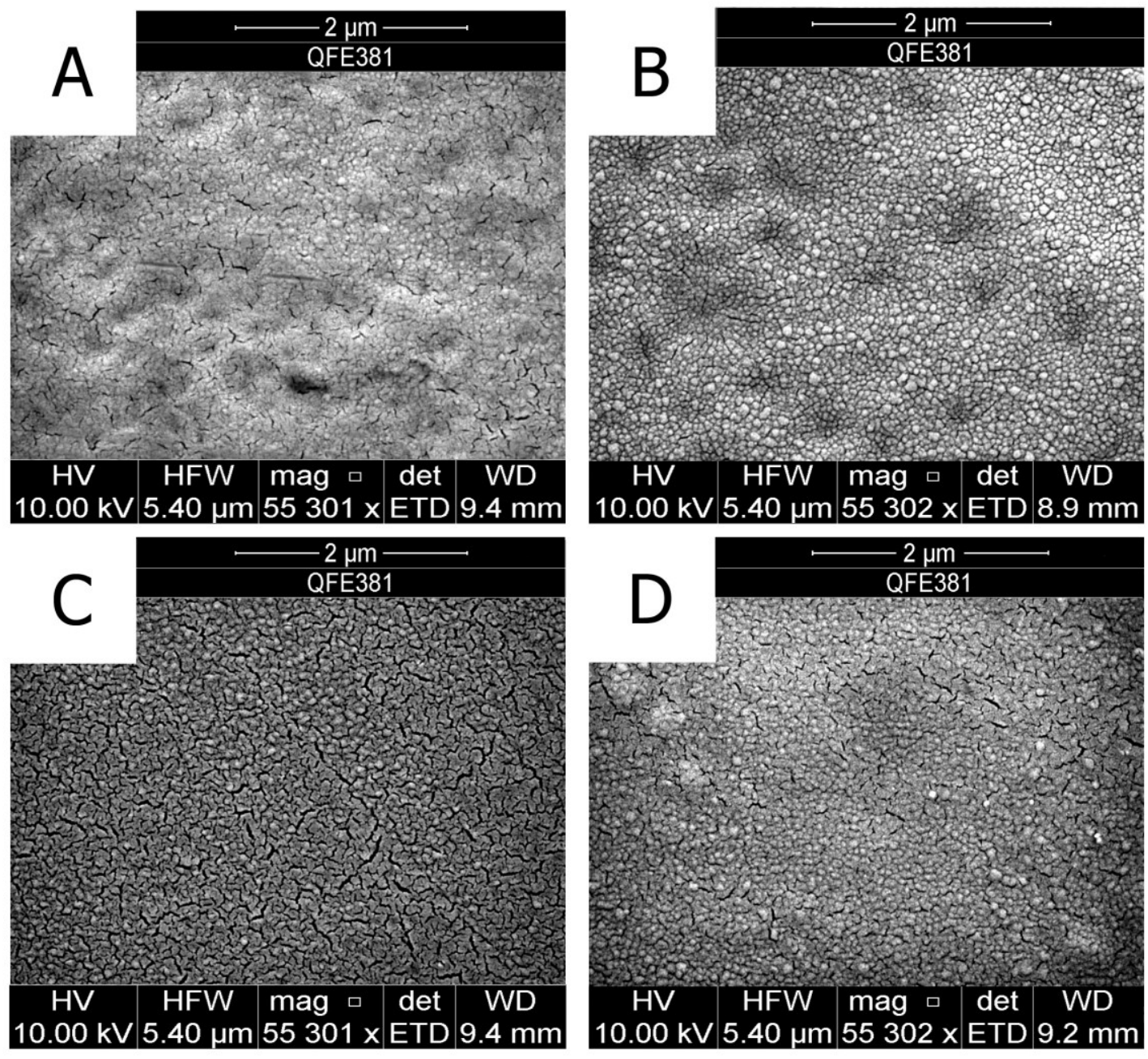

Figure 2. SEM micrographs showing surface topography of the tantalum oxynitride coatings

The results of XRD analysis of samples A and B are presented in Figure 3. Samples C and D showed amorphous XRD patterns, and therefore are not shown in the figure. As coatings $\mathrm{C}$ and D had a much lower nitrogen content compared to samples A and B, their amorphous structure may be explained by the higher crystallization temperature required for tantalum oxide, rather than for tantalum oxynitride (tantalum oxide reportedly crystallizes at temperatures of $973 \mathrm{~K}$ and higher $[17,18])$. Hence, it is possible to conclude that decreasing the nitrogen flow from 20 to $10 \mathrm{sccm}$ led to amorphisation of the films due to an increase in crystallisation temperature. 
The XRD pattern of sample A produced with a higher oxygen flow (30\% OEM signal) reveals a well-defined peak at $2 \theta=32.6^{\circ}$ that can be attributed to monoclinic TaON ( $\left.\begin{array}{lll}1 & 1 & 1\end{array}\right)$ (JCPDS: 201235); another strong peak at $2 \theta=22.9^{\circ}$ belongs to orthorhombic $\mathrm{Ta}_{2} \mathrm{O}_{5}\left(\begin{array}{lll}0 & 0 & 1\end{array}\right)$ (JCPDS: 250922). Several weaker peaks seen on the XRD pattern of sample $A$ at $2 \theta=46.7^{\circ}, 52.8^{\circ}$ and $58.0^{\circ}$ were attributed to different orientations of orthorhombic $\mathrm{Ta}_{2} \mathrm{O}_{5}:\left(\begin{array}{lll}0 & 0\end{array}\right),\left(\begin{array}{lll}0 & 1 & 2\end{array}\right)$ and $\left(\begin{array}{l}2 \\ 2\end{array}\right.$ 0), respectively (JCPDS: 25-0922).

The XRD pattern of sample B exhibits several relatively weak peaks, including monoclinic TaON peaks at $2 \theta=25.3^{\circ}\left(\begin{array}{lll}1 & 1 & 0\end{array}\right), 32.6^{\circ}\left(\begin{array}{lll}1 & 1 & 1\end{array}\right)$ and $35.0^{\circ}\left(\begin{array}{lll}0 & 0 & 2\end{array}\right)$ (JCPDS: 20-1235) and orthorhombic $\mathrm{Ta}_{2} \mathrm{O}_{5}\left(\begin{array}{lll}0 & 0 & 1\end{array}\right)$ peak at $2 \theta=22.9^{\circ}$.

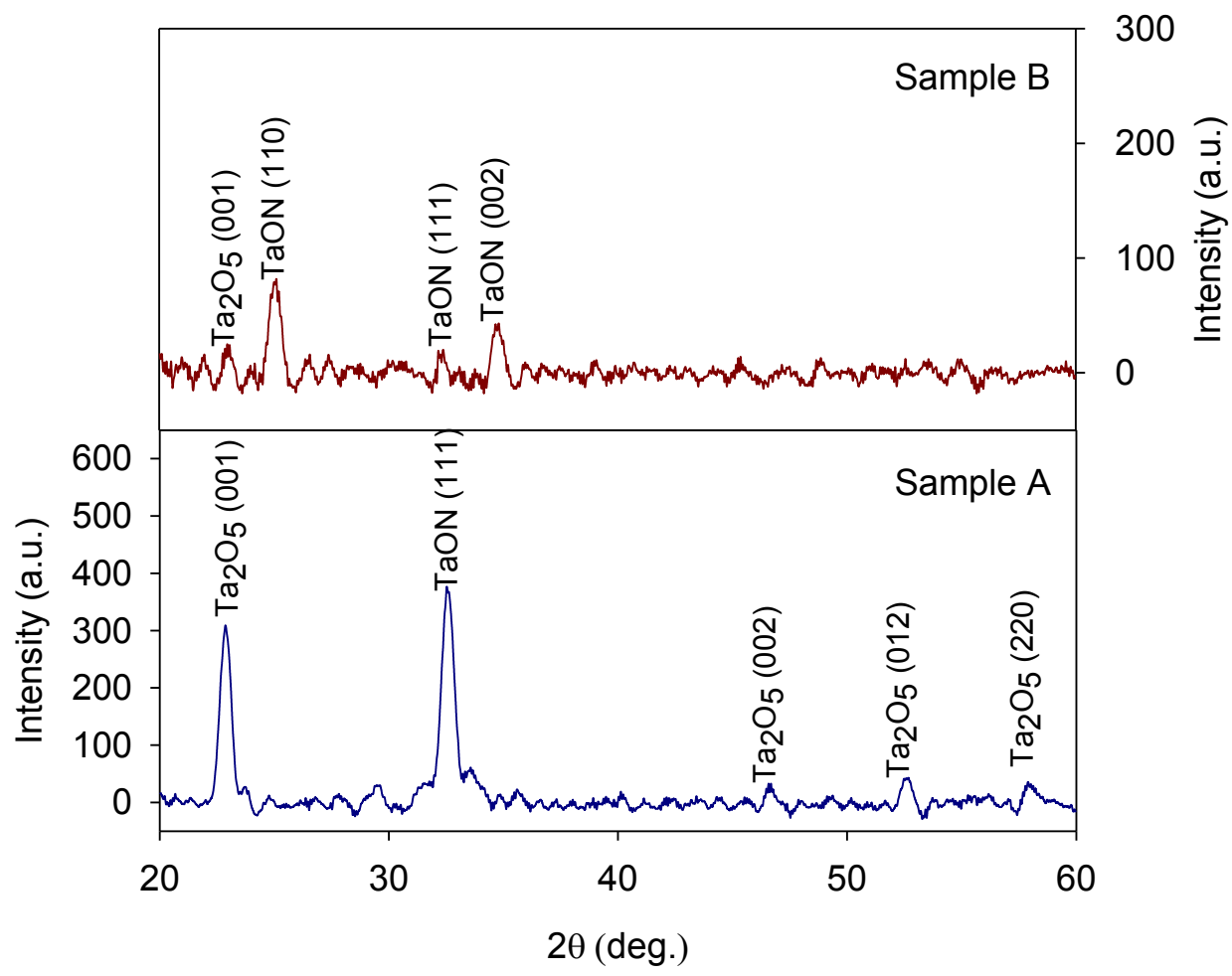

Figure 3. GIXRD patterns of tantalum oxynitride samples A and B deposited on glass substrates

The optical band gap values of the coatings were calculated using the Tauc plot method, based on coating transmittance data. According to this method, the optical band gap of a semiconductor can be calculated using the Tauc equation [19]: 


$$
\alpha h v=\left(h v-E_{g}\right)^{1 / n}
$$

Where $\alpha$ is absorbance coefficient, $h$ is Plank's constant, $v$ is the frequency of vibration, $E_{\mathrm{g}}$ is energy band gap, $\mathrm{n}$ is the exponent that denotes the nature of sample transition. Both tantalum oxide and tantalum oxynitride are indirect band gap semiconductors [20, 21], so in this case $\mathrm{n}=2$.

The coating transmittance information can be used for band gap calculation:

$$
T=e^{-\alpha d}
$$

Where $d$ is the thickness of the coating. Therefore, the band gaps were calculated by plotting $(\alpha h v)^{1 / 2}$ versus $h v$ and then extrapolating the linear region to the abscissa. The predominant crystal phase band gap information of all the coatings is summarised in Table 1, where it can be seen that samples A and B, containing tantalum oxynitride, are characterized with significantly lower band gap values compared to samples $\mathrm{C}$ and $\mathrm{D}$. The surface roughness information is summarised in Table 1 - it reveals that the surface roughness of coatings A and B was significantly higher, compared to coatings $\mathrm{C}$ and $\mathrm{D}$, which is in good agreement with appearance of the coatings seen on SEM images. The values of the first order rate constant for various coatings are presented in Figure 4. A sample of commercially available photocatalytic coating (Pilkington Activ) of identical size was used for comparison. The photocatalytic activity of sample A was much higher than that of the commercial product. Sample B also showed considerable visible light activity, while samples $\mathrm{C}$ and $\mathrm{D}$ had little or no activity under visible light. As expected, samples A and B characterised with low band gaps and a crystalline structure, showed relatively high activity for the degradation of MB under visible light. Similar surface roughness values obtained for coatings A and B allow an assumption that the difference in the photocatalytic activity values can be attributed rather to variation of coatings composition and optical band gaps, rather than to their morphology. 


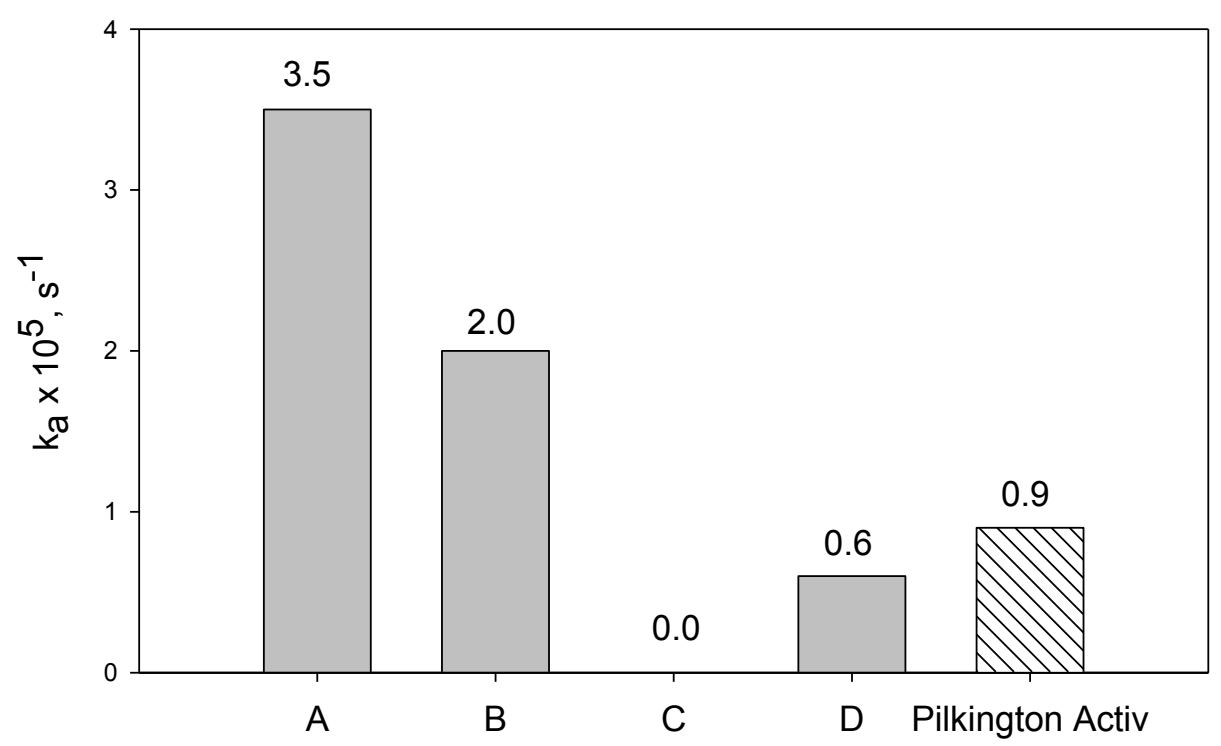

Figure 4: First order rate constants of photocatalytic MB degradation reaction of TaON coatings and Pilkington Activ under visible light

In summary, based on the results presented, tantalum oxynitride coatings can be deposited by mid-frequency pulsed-dc magnetron sputtering to be used as visible-light activated photocatalytic materials. Although all of the coatings analysed contained some amount of nitrogen, a tantalum oxy-nitride crystalline peak was seen only in the diffraction patterns of coatings $\mathrm{A}$ and $\mathrm{B}$, deposited at the higher nitrogen flow rate. Coatings $\mathrm{C}$ and $\mathrm{D}$ consisted mainly of tantalum oxide, and therefore did not develop a detectable crystal structure, even after annealing at $873 \mathrm{~K}$ (tantalum oxide reportedly requires annealing at $973 \mathrm{~K}$ or higher to develop crystallinity). The band gap data confirmed the initial suggestions on coating composition samples A and B were characterised with very low band gaps, while for the coatings produced at a lower nitrogen flow rate, the band gaps were significantly higher. Coatings A and B showed high levels of methylene blue decomposition under visible light irradiation, which is in good agreement with the presence of crystalline $\mathrm{TaON}$ and the low band gaps of these coatings. Both of these coatings were considerably more efficient for MB decomposition than the sample of commercially available Pilkington Activ glass of identical geometry. The low transparency and 
dark colour of tantalum oxynitride coatings precludes their application in fields where high optical transparency is required (e.g. photocatalytic glass); therefore the authors suggest that these coatings may be used in indoor photocatalytic materials where traditional UV light activated photocatalysts cannot be used.

\section{References}

[1] Kumar KJ, Raju NRC, Subrahmanyam A. Properties of pulsed reactive DC magnetron sputtered tantalum oxide $\left(\mathrm{Ta}_{2} \mathrm{O}_{5}\right)$ thin films for photocatalysis. Surface and Coatings Technology. 2011;205, Supplement 2:S261-S4.

[2] Takahara Y, Kondo JN, Takata T, Lu D, Domen K. Mesoporous Tantalum Oxide. 1. Characterization and Photocatalytic Activity for the Overall Water Decomposition. Chemistry of Materials. 2001;13:1194-9.

[3] Sreethawong T, Ngamsinlapasathian S, Suzuki Y, Yoshikawa S. Nanocrystalline mesoporous Ta2O5-based photocatalysts prepared by surfactant-assisted templating sol-gel process for photocatalytic $\mathrm{H}_{2}$ evolution. Journal of Molecular Catalysis A: Chemical. $2005 ; 235: 1-11$.

[4] Hsieh JH, Li C, Liang HC. Structures and photocatalytic behavior of tantalum-oxynitride thin films. Thin Solid Films. 2011;519:4699-704.

[5] Cristea D, Crisan A, Barradas NP, Alves E, Moura C, Vaz F, et al. Development of tantalum oxynitride thin films produced by PVD: Study of structural stability. Applied Surface Science. 2013;285, Part A:19-26. 
[6] Takata T, Hitoki G, Kondo JN, Hara M, Kobayashi H, Domen K. Visible-light-driven photocatalytic behavior of tantalum-oxynitride and nitride. Research on Chemical Intermediates. 2007;33:13-25.

[7] Hitoki G, Takata T, Kondo JN, Hara M, Kobayashi H, Domen K. An oxynitride, TaON, as an efficient water oxidation photocatalyst under visible light irradiation $500 \mathrm{~nm}$ ). Chemical Communications. 2002:1698-9.

[8] Hara M, Hitoki G, Takata T, Kondo JN, Kobayashi H, Domen $\mathrm{K}$. TaON and $\mathrm{Ta}_{3} \mathrm{~N}_{5}$ as new visible light driven photocatalysts. Catalysis Today. 2003;78:555-60.

[9] Hsieh JH, Chang CC, Cherng JS, Hsu FY. Optical properties and hydrophilic behaviors of $\mathrm{TaO}_{\mathrm{x}} \mathrm{N}_{\mathrm{y}}$ thin films with and without rapid thermal annealing. Thin Solid Films. 2009;517:47114.

[10] Kou J, Li Z, Yuan Y, Zhang H, Wang Y, Zou, Z. Visible-light-induced photocatalytic oxidation of polycyclic aromatic hydrocarbons over tantalum oxynitride photocatalysts. Environmental Science and Technology. 2009; 43:2919-2923.

[11] Nakamura R, Tanaka T, Nakato Y. Oxygen photoevolution on a tantalum oxynitride photocatalyst under visible-light irradiation: How does water photooxidation proceed on a metal-oxynitride surface? Journal of Physical Chemistry B. 2005; 109: 8920-8927.

[12] Ratova M, Kelly PJ, West GT, Iordanova I. Enhanced properties of magnetron sputtered photocatalytic coatings via transition metal doping. Surface and Coatings Technology. 2013;228, Supplement 1:S544-S9.

[13] Ratova M, West G, Kelly P. Optimization Studies of Photocatalytic Tungsten-Doped Titania Coatings Deposited by Reactive Magnetron Co-Sputtering. Coatings. 2013;3:194-207. [14] Noimark S, Dunnill CW, Parkin IP. Shining light on materials — A self-sterilising revolution. Advanced Drug Delivery Reviews. 2013;65:570-80.

[15] Cristea D, Constantin D, Crisan A, Abreu CS, Gomes JR, Barradas NP, et al. Properties of tantalum oxynitride thin films produced by magnetron sputtering: The influence of processing parameters. Vacuum. 2013;98:63-9. 
[16] Venkataraj S, Kittur H, Drese R, Wuttig M. Multi-technique characterization of tantalum oxynitride films prepared by reactive direct current magnetron sputtering. Thin Solid Films. $2006 ; 514: 1-9$

[17] Zhu Y, Yu F, Man Y, Tian Q, He Y, Wu N. Preparation and performances of nanosized $\mathrm{Ta}_{2} \mathrm{O}_{5}$ powder photocatalyst. Journal of Solid State Chemistry. 2005;178:224-9.

[18] Guo G, Huang J. Preparation of mesoporous tantalum oxide and its enhanced photocatalytic activity. Materials Letters. 2011;65:64-6.

[19] Tauc J, Grigorovici R, Vancu A. Optical Properties and Electronic Structure of Amorphous Germanium. physica status solidi (b). 1966;15:627-37.

[20] Allam NK, Shaheen BS, Hafez AM. Layered Tantalum Oxynitride Nanorod Array Carpets for Efficient Photoelectrochemical Conversion of Solar Energy: Experimental and DFT Insights. ACS Applied Materials \& Interfaces. 2014.

[21] Yu H, Zhu S, Yang X, Wang X, Sun H, Huo M. Synthesis of Coral-Like Tantalum Oxide Films via Anodization in Mixed Organic-Inorganic Electrolytes. PLoS ONE. 2013;8:66447. 